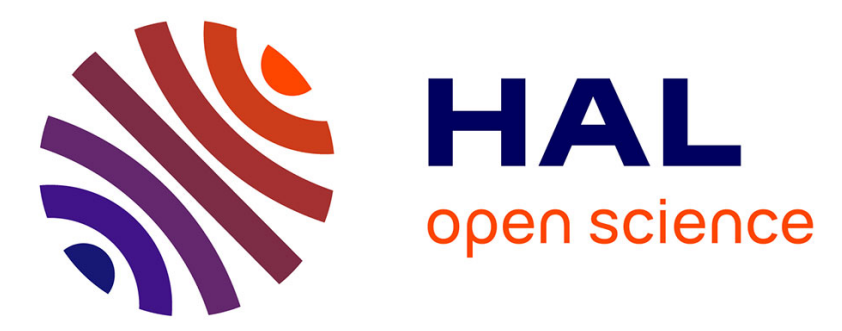

\title{
Comparison of risk factors and perinatal outcomes in early onset and late onset preeclampsia: A cohort based study in Reunion Island
}

Silvia Iacobelli, Francesco Bonsante, Pierre-Yves Robillard

\section{- To cite this version:}

Silvia Iacobelli, Francesco Bonsante, Pierre-Yves Robillard. Comparison of risk factors and perinatal outcomes in early onset and late onset preeclampsia: A cohort based study in Reunion Island. Journal of Reproductive Immunology, 2017, 123, pp.12 - 16. 10.1016/j.jri.2017.08.005 hal-01631488

\section{HAL Id: hal-01631488 \\ https: / hal.univ-reunion.fr/hal-01631488}

Submitted on 14 Nov 2017

HAL is a multi-disciplinary open access archive for the deposit and dissemination of scientific research documents, whether they are published or not. The documents may come from teaching and research institutions in France or abroad, or from public or private research centers.
L'archive ouverte pluridisciplinaire HAL, est destinée au dépôt et à la diffusion de documents scientifiques de niveau recherche, publiés ou non, émanant des établissements d'enseignement et de recherche français ou étrangers, des laboratoires publics ou privés. 


\title{
Comparison of risk factors and perinatal outcomes in early onset and late onset preeclampsia: A cohort based study in Reunion Island
}

\author{
Silvia Iacobelli ${ }^{\mathrm{a}, \mathrm{b}, *}$, Francesco Bonsante ${ }^{\mathrm{a}, \mathrm{b}}$, Pierre-Yves Robillard ${ }^{\mathrm{a}, \mathrm{b}}$ \\ a Réanimation Néonatale et Pédiatrique, Néonatologie, CHU La Réunion, BP 350, 97448 Saint Pierre Cedex, France

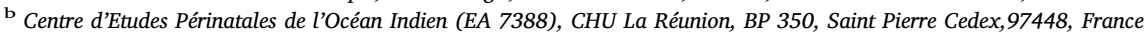

\begin{abstract}
A B S T R A C T
Clinical differences, maternal risk factors and pregnancy outcomes of deliveries complicated by early- (de-livery $<34$ weeks) and late-onset (delivery $\geq 34$ weeks) preeclampsia were studied in a cohort of women in Reunion Island during 15 years (period 2001-2015; $\mathrm{N}=62,230$ pregnancies). The overall preeclampsia rate in singleton pregnancies was $2.37 \%$. Early- and late-onset preeclampsia rates were $0.75 \%$ and $1.5 \%$ respectively, and the trend for each type of disease was stable over time. In both form of preeclampsia, smoking during pregnancy was a protective factor and associated risk factors were: older age, primiparity, pre-existing diabetes, chronic hypertension, higher pre-pregnancy body mass index and obesity, infertility treatment, history of renal disease and hypercholesterolemia (all $p<0.05$ ). The rate of caesarean section, medically-induced delivery and impaired foetal and neonatal outcomes were significantly higher in preeclamptic women (all $\mathrm{p}<0.0001$ ). When comparing early- versus late-onset preeclampsia, the only difference was the older maternal age in pri-miparae with early-onset preeclampsia $(\mathrm{p}=0.02)$, and the two groups of preeclamptic women were similar in terms of maternal risk factors, with the exception of higher rates of chronic hypertension in early-onset preeclampsia $(\mathrm{p}=0.02)$. Foetal and neonatal outcomes were evaluated after adjustment for gestational age at delivery and no difference was detected between early- and late-onset preeclamptic women. These analyses failed to identify a specific phenotype of preeclampsia in terms of predisposition or pre-existing risk factors for one form or another. Gestational age at delivery was the most important predictor for offspring outcome.
\end{abstract}

\section{Introduction}

${ }^{1}$ It is well recognized that preeclampsia is a heterogeneous syndrome and that the clinical characteristics of the early-onset preeclampsia (EO-PE, gestational age at delivery $<34$ weeks) and lateonset disease (LO-PE, $\geq 34$ weeks) are different (Sibai et al., 2005). The pathophysiology of the two disorders is also supposed to be different: Vatten et al. have suggested that preterm delivered preeclampsia associated with low birthweight may be caused by underlying placental abnormality, whereas pre-eclampsia delivered at term may represent a mixture of conditions, ranging from mild pre-eclampsia with moderate placental affection to hypertensive conditions in pregnancies without placental dysfunction. (Vatten and Skjaerven, 2004). Recently, Redman et al. have suggested that the LO-PE form also relies on the placenta, but that the placenta perfusion problems at term are due to a different placenta problem than the dysfunctional spiral artery remodelling pathway, which is more typical of the EO-PE pathophysiology (Redman et al., 2014; Redman and Staff, 2015).

Several publications have described the associated maternal morbidities, birth outcomes, clinical and laboratory features of the two preeclampsia types (Ny and Cheng, 2016; Kucukgoz Gulec et al., 2013; Lisonkova and Joseph, 2013). The mother's younger age at first birth (Robillard et al., 2007) and some maternal risk factors (such as metabolic syndrome and hypertension) have been addressed for having important roles in development of the EO- and the LO-form, respectively. Also, maternal, foetal and neonatal complications are different in EO-PE compared to LO-PE (Aksornphusitaphong and Phupong, 2013; Lisonkova et al., 2014).

In general, within a population, both forms are represented, with the vast majority of women developing LO-PE (and so, mild neonatal signs) and a minority presenting EO-PE (and so, prematurity and impaired perinatal outcome) (Chaiworapongsa et al., 2014). However, we

\footnotetext{
* Corresponding Author at: Néonatologie, Réanimation Néonatale et Pédiatrique, Centre Hospitalier Universitaire La Réunion, France. Centre d'Etudes Périnatales de l'Océan Indien, CHU La Réunion, France.

E-mail address: silvia.iacobelli@chu-reunion.fr (S. Iacobelli).

${ }^{1}$ Abbreviations: BMI (body mass index), EO-PE (early-onset preeclampsia); IVF (in vitro fertilization), ICSI (intra-cytoplasmic sperm injection); IUFD (intrauterine foetal death); LO-PE (late-onset preeclampsia)], MTP (medical termination of pregnancy); SGA (small for gestational age).
} 
recently showed that predominance of early- or late-onset preeclampsia may have huge geographical differences as the rate of EO-PE (defined as preeclampsia delivered before 34 weeks of gestation) was strikingly high (31.2\% of all preeclampsia) in a cohort from Reunion Island, compared to other countries (8-10\%) (Iacobelli et al., 2015).

Reunion Island is a French department in the Southern Indian Ocean. The peculiarity of this tropical region lays in the multiethnic origin of inhabitants [Africa and intermixed population (50\%), Europe (27\%), India (20\%) and China (3\%)]. Compared to Europe and mainland France, there is a younger reproductive population (the mean age at primiparity is approximately 23 years). Finally, accessibility to maternity services is easy, and high-quality care is provided free of charge by the French healthcare system.

The aim of the present study was to compare the clinical differences, the maternal risk factors and the pregnancy outcomes between EO-PE and LO-PE in this particular population of preeclamptic women with a very high prevalence of preterm delivery.

\section{Materials and methods}

\subsection{Design and study population}

"Southern Reunion" identifies a specific geographic and health area of our department, with 5400 deliveries on average per year, occurring in three facilities ( 2 primary care and 1 tertiary care center). In this territory, all preeclampsia are referred to the tertiary care maternity of Saint Pierre University hospital.

This was an observational cohort study of all singleton preeclamptic pregnancies who delivered in this third level center over 15 years (January 2001 to December 2015).

\subsection{Clinical data and variables}

The study sample was drawn from the hospital perinatal database, which prospectively records data of all mother-infant pairs since 2001. Information is collected at the time of delivery and at the time of infant hospital discharge and regularly audited by appropriately trained staff; for the purpose of this study, records have been validated and have been used anonymously. Maternal characteristics and clinical risk factors examined for potential association with preeclampsia included: maternal age, parity and gravidity, marital status, education, smoking or alcohol assumption during pregnancy, infertility treatment, prepregnancy body mass index (BMI), diabetes mellitus, chronic hypertension prior to pregnancy, coagulopathy, hypercholesterolemia, history of preeclampsia, history of renal or thyroid disease and congenital malformation. The following delivery and pregnancy outcomes were analyzed: medically induced delivery, caesarean section, abnormal foetal heart rate, postpartum haemorrhage, intrauterine foetal death [(IUFD) in utero or intrapartum death of a foetus delivered at 22 weeks of gestation or later], medical termination of pregnancy (MTP), early neonatal death (death between 1 and 7 days of life) and perinatal death (defined as IUFD + MTP + early neonatal death), HELLP syndrome, and eclampsia. The neonatal outcomes of interest were: gestational age at birth, birth weight, sex, Apgar@1 min $\leq 3$, small for gestational age, (SGA, according to Brenner et al., 1976) and need for intubation at birth.

\subsection{Definition of exposure}

Preeclampsia was defined according to the international recommendations which were used during most of the period covered in this study: systolic blood pressure $\geq 140 \mathrm{mmHg}$ or $\geq$ diastolic $90 \mathrm{mmHg}$ at bed rest on at least two occasions $6 \mathrm{~h}$ apart, and proteinuria (excretion of $\geq 0.3 \mathrm{~g} /$ day, or at least $1+$ on a urine reagent strip), measured after the 20th week of pregnancy (No authors listed, 2000).

Preeclampsia outcome was categorized in two groups: EO-PE and
LO-PE defined as delivery before 34.0 and $\geq 34.0$ weeks, respectively.

\subsection{Statistical analysis}

Categorical variables were presented as frequencies and continuous variables as means \pm SDs.

Bivariate comparisons were performed using $\chi 2$ test, or Fisher exact test for qualitative variables and ANOVA or Kruskal-Wallis test when appropriate.

First, women with preeclampsia were compared to women without preeclampsia. Second, EO-PE were compared to LO-PE. In a second stage of analysis, we estimated the effect of dichotomizing gestational age at delivery before 37.0 and $\geq$ at 37 weeks on maternal characteristics and risk factors. Comparative analysis of delivery and neonatal outcomes was adjusted for gestational age at birth when appropriate.

Because at bivariate analysis preeclamptic women had significantly higher rates of pre-pregnancy BMI and BMI $>30 \mathrm{~kg} / \mathrm{m}^{2}$, and following the previous observation of the impressive increase of obesity in pregnant women at Reunion Island (Robillard, 2014), in a supplementary analysis, we plotted the trend of obesity rate with that of both EO-PE and LO-PE over the study period in the observed population. A $\mathrm{p}$ value $<0.05$ was considered significant.

\subsection{Ethics}

This study was conducted in accordance with French legislation. As per to the French law a specific approval of an ethics committee is not required for this non-interventional study based on retrospective, anonymized data and written consent is not needed.

\section{Results}

\subsection{Epidemiology of preeclampsia}

Over the study period 62,330 deliveries occurred in the maternity department and were recorded in the database. The incidence of preeclampsia in this entire cohort was $2.37 \%$, with rates of $2.29 \%$ and $6.85 \%$ in singleton and multiple deliveries respectively.

For the purpose of the study, only singleton deliveries $(N=61,062)$ were analyzed. The total number of preeclampsia over the study period was 1397 and the frequency of EO-PE and LO-PE was respectively 0.75 (464 of 61,062) and 1.5 (933 of 61,062) per 100 deliveries. Among all preeclampsia, $33.21 \%$ were EO and 66.79 were LO. Among alive births from preeclamptic delivery, $60 \%$ were preterm (born less than 37 weeks of gestation) and $40 \%$ were at term ( $\geq 37$ weeks of gestation). Among all infants $413(31 \%)$ were $<34,386(29 \%)$ were $34-36$ and 534 (40\%) were $\geq 37$ weeks of gestation.

\subsection{Sociodemographic characteristic of the study population and comparison between EO-PE and LO-PE}

Table 1 shows sociodemographic characteristics of the study population. Preeclamptic women were in general older and more often primiparae than no preeclamptic ones. The only difference when comparing EO-PE and LO-PE was the older age of primiparae with EOPE.

When dichotomizing preeclampsia into preterm and term delivered groups ( $<37$ and $\geq 37$ weeks of gestation, respectively) we found statistically significant differences between the groups for marital status and education (lower rates of "single" marital status and lower education level in EO-PE compared to LO-PE, $\mathrm{p}$ respectively $=0.03$ and 0.04, data not shown). Sociodemographic characteristics of preeclamptic women were not different in patients who delivered a SGA infant (data not shown). 
Table 1

Sociodemographic characteristics of the study population and comparison between EO-PE and LO-PE.

\begin{tabular}{|c|c|c|c|c|c|c|}
\hline Variables & No PE N =59,665 N (\%) & LO-PE N = 933 N (\%) & EO-PE N = 464 N (\%) & $\begin{array}{l}\text { LO-PE vs No PE p } \\
\text { value }\end{array}$ & EO-PE $v s$ No PE p value & $\begin{array}{l}\text { EO-PE } v s \text { LO-PE } \mathrm{p} \\
\text { value }\end{array}$ \\
\hline Age, years" & $27.6 \pm 6.6$ & $28.5 \pm 7.0$ & $29.2 \pm 6.8$ & $<0.0001$ & $<0.0001$ & ns \\
\hline Age, years" (primipara only) & $23.7 \pm 5,5$ & $24.8 \pm 6.0$ & $26.1 \pm 6.6$ & $<0.0001$ & $<0.0001$ & 0.02 \\
\hline Adolescent (12-17 years) & $2709(4.5)$ & $36(3.9)$ & $17(3.7)$ & ns & ns & ns \\
\hline Age older than 35 years & $8354(14.0)$ & $186(19.9)$ & $99(21.3)$ & $<0.0001$ & $<0.0001$ & ns \\
\hline Primiparity & $22,153(37.1)$ & $455(48.8)$ & $208(44.8)$ & $<0.0001$ & $<0.0001$ & ns \\
\hline Primigravidity & $16,479(27.6)$ & $337(36.1)$ & $151(32.5)$ & $<0.0001$ & 0.02 & 0.03 \\
\hline Single & $21,456(36.1)$ & $352(37.8)$ & $165(35.6)$ & ns & ns & ns \\
\hline High school or university & $31,030(54.2)$ & $460(51.5)$ & $223(53.1)$ & ns & ns & ns \\
\hline
\end{tabular}

* Values are expressed as mean $\pm \mathrm{SD}$

\subsection{Maternal and clinical risk factors in the study population and comparison between EO-PE and LO-PE}

All the considered gestational morbidities, as also obesity and higher pre-pregnancy BMI were significantly more prevalent in preeclamptic woman, compared to no preeclamptic ones, with no difference between EO-PE and LO-PE excepted for a rate of chronic hypertension significantly higher in EO-PE (Table 2).

When dichotomizing preeclampsia into preterm and term delivered groups ( $<37$ and $\geq 37$ weeks of gestation, respectively) all the trends for women characteristics and risk factors remained similar and we found the following statistically significant differences between the two groups: higher rates of preexisting diabetes and lower rates of obesity in EO-PE (p respectively 0.04 and 0.02 , data not shown).

\subsection{Delivery outcomes in the study population and comparison between EO- $P E$ and $L O-P E$}

Delivery outcomes were different in preeclamptic women compared to no preeclamptic ones. The risk of medically induced delivery and that of caesarian section were higher in EO-PE compared to LO-PE, even after adjustment for gestational age (Table 3).

3.5. Foetal and neonatal outcomes in the study population and comparison between EO-PE and LO-PE

Gestational age and birth weight were lower in infants from preeclamptic mothers compared to no preeclamptic ones and the former presented significantly higher rates of SGA. Pregnancies complicated by EO-PE or LO-PE were more often associated with unfavorable foetal and neonatal outcomes. After adjustment for gestational age, foetal and neonatal outcomes did not differ significantly between EO- and LO-PE. However, the rate of MTP was significantly higher in EO-PE. (Table 4).
3.6. Trends of EO-PE and LO-PE over the study period and comparison with the obesity trend in the study population

As shown in Fig. 1, the rates of EO-PE and LO-PE did not change in our population during the study period, despite a significant parallel increase of the obesity rate.

\section{Discussion}

This study aimed to compare the clinical differences, the maternal risk factors and the pregnancy outcomes between EO-PE and LO-PE in Southern Reunion Island. Despite some specificities of this population, in particular the very high prevalence of preterm birth from preeclamptic mothers already reported (Iacobelli et al., 2015) and confirmed here, the present study failed to identify any particular difference when comparing the two types of preeclampsia. The most impressive difference between the two groups refereed to the obvious more unfavorable neonatal outcome in infants born from EO-PE mothers, but this was merely dependent from the impact of a more preterm delivery.

Among socio-demographic factors, none conferred a relatively higher risk for EO-PE (as opposed to LO-PE), with the only exception of older age in primiparae. These findings are not consistent and even antithetic with previous works which emphasized that the early-onset disease in primiparae is prominent in adolescent and younger unmarried women (Robillard et al., 2007). Other investigations (Stubert et al., 2014; Madazli et al., 2014), having a sample size smaller than our, also failed to identify differences in maternal age when comparing EO-PE and LO-PE.

Several maternal risk factors of preeclampsia in our population were pre-existing morbidities that also represent risk factors for cardiovascular disorders (hypertension, diabetes, obesity, renal disease and hypercholesterolemia). All these diseases have long been considered as classical markers for preeclampsia at antenatal booking (Milne et al.,

Table 2

Obstetric risk factors of the study population and comparison between EO-PE and LO-PE.

\begin{tabular}{|c|c|c|c|c|c|c|}
\hline Variables & $\begin{array}{l}\text { No PE N }=59,665 \mathrm{~N} \\
(\%)\end{array}$ & LO-PE N = 933 N (\%) & EO-PE N = 464 N (\%) & $\begin{array}{l}\text { LO-PE } v s \text { No PE } p \\
\text { value }\end{array}$ & $\begin{array}{l}\text { EO-PE } v s \text { No PE } \mathrm{p} \\
\text { value }\end{array}$ & $\begin{array}{l}\text { EO-PE } v s \text { LO-PE } \mathrm{p} \\
\text { value }\end{array}$ \\
\hline Gestational diabetes & $5978(10.0)$ & $132(14.2)$ & 55 (11.9) & 0.004 & NS & ns \\
\hline Pre-existing diabetes & $816(1.5)$ & $29(3.5)$ & $18(4.3)$ & $<0.0001$ & $<0.0001$ & ns \\
\hline Alcohol & $389(0.7)$ & $6(0.7)$ & $3(0.6)$ & ns & ns & ns \\
\hline Smoking during pregnancy & 7397 (12.4) & $83(8.9)$ & $42(9.1)$ & 0.002 & 0.04 & ns \\
\hline Chronic hypertension & $882(1.5)$ & $78(8.4)$ & $57(12.3)$ & $<0.0001$ & $<0.0001$ & 0.02 \\
\hline Pre-pregnancy BMI $\left(\mathrm{Kg} / \mathrm{m}^{2}\right)^{*}$ & $24.4 \pm 5.8$ & $26.9 \pm 6.9$ & $26.1 \pm 6.0$ & $<0.0001$ & $<0.0001$ & ns \\
\hline $\mathrm{BMI} \geq 30 \mathrm{~kg} / \mathrm{m}^{2}$ & 8975 (15.7) & $252(28.8)$ & $99(25.3)$ & $<0.0001$ & $<0.0001$ & ns \\
\hline IVF, ICSI & $327(0.5)$ & $10(1.1)$ & $8(1.7)$ & 0.03 & 0.0007 & $\mathrm{~ns}$ \\
\hline Coagulopathy & $171(0.28)$ & $5(0.53)$ & $6(1.29)$ & ns & $<0.0001$ & ns \\
\hline Thyroid disease & $783(1.3)$ & $15(1.6)$ & $12(2.6)$ & $\mathrm{ns}$ & 0.009 & ns \\
\hline Renal disease & $143(0.24)$ & $10(1.07)$ & $8(1.7)$ & 0.02 & 0.02 & ns \\
\hline Hypercholesterolemia & $26(0.04)$ & $3(0.32)$ & $2(0.43)$ & 0.01 & 0.01 & ns \\
\hline
\end{tabular}

\footnotetext{
* Values are expressed as mean $\pm \mathrm{SD}$
} 
Table 3

Delivery outcomes and complications of the study population and comparison between EO-PE and LO-PE.

\begin{tabular}{|c|c|c|c|c|c|c|c|}
\hline Variables & $\begin{array}{l}\text { No PE N }=59,665 \mathrm{~N} \\
(\%)\end{array}$ & $\begin{array}{l}\text { LO-PE N = } 933 \\
\mathrm{~N}(\%)\end{array}$ & $\begin{array}{l}\text { EO-PE N }=464 \\
N(\%)\end{array}$ & $\begin{array}{l}\text { LO-PE } v s \text { No PE } \mathrm{p} \\
\text { value }\end{array}$ & $\begin{array}{l}\text { EO-PE vs No PE } p \\
\text { value }\end{array}$ & $\begin{array}{l}\text { EO-PE } v s \text { LO-PE } \mathrm{p} \\
\text { value }\end{array}$ & $\begin{array}{l}\text { EO-PE } v s \text { LO-PE p } \\
\text { adjusted for GA }\end{array}$ \\
\hline Caesarean section & $9034(15.1)$ & $412(44.2)$ & $409(87.5)$ & $<0.0001$ & $<0.0001$ & $<0.0001$ & $<0.0001$ \\
\hline $\begin{array}{l}\text { Medically - Induced } \\
\text { delivery }\end{array}$ & $12390(20.7)$ & $605(64.8)$ & $49(10.6)$ & $<0.0001$ & $<0.0001$ & $<0.0001$ & $<0.0001$ \\
\hline $\begin{array}{l}\text { Abnormal Foetal Hearth } \\
\text { Rate }\end{array}$ & $8731(15.2)$ & $244(27.0)$ & $157(39.4)$ & $<0.0001$ & $<0.0001$ & $<0.0001$ & ns \\
\hline Post-partum Haemorrhage & $1406(3.2)$ & $40(5.2)$ & $5(1.5)$ & 0.002 & $\mathrm{~ns}$ & 0.005 & ns \\
\hline HELLP Syndrome & - & $23(2.5)$ & $40(8.6)$ & - & - & $<0.0001$ & ns \\
\hline Eclampsia & - & $31(3.3)$ & $12(2.6)$ & - & - & ns & ns \\
\hline
\end{tabular}

2005; Steegers et al., 2010) and one recent review clearly underlined that metabolic syndrome and pre-existing hypertension are more common risk factors in women with late onset disease compared to those with the early- one (Chaiworapongsa et al., 2014). On the contrary, in our population women with EO-PE were not exempted from these chronic systemic conditions and compared to LO-PE they even exhibited higher rates of pre-pregnancy hypertension. This finding is not new, and it is consistent with that of a population-based study from Lisonkova et al., 2014, which analyzed 14,201 preeclamptic women among 456,668 singleton deliveries in Washington State, as also with the results of a case-control analysis in preeclamptic women in Thailand (Aksornphusitaphong and Phupong, 2013)., We found a statistically significant difference for chronic hypertension when comparing EO versus LO PE in our cohort $(\mathrm{p}=0.02)$. This result may simply reveal the severity of the underlying disorder in preeclamptic mothers that, as a consequence, are more likely to have a preterm delivery.

Mode of delivery was more often medically-induced and by caesarean section in preeclamptic pregnancies compared to their counterpart, with significantly higher rates in EO-PE women, and this association remained valid once adjustment for gestational age was made. In one previous study (Iacobelli et al., 2015) we showed that indication to delivery was compliant to guidelines in $92 \%$ of all preeclampsia in our maternity care, with $44 \%$ and $48 \%$ of, respectively, maternal and foetal indications. So, the very high rates of delivery induction due to medical decision in our cohort may be the reflex of the preeclampsia severity in Reunion island population. Moreover, the prevalence of eclampsia was similar within the two groups.

In our cohort, and as reported by others (Madazli et al., 2014; Elvedi Gasparovic et al., 2015; Stubert et al., 2014), EO-PE showed substantially higher risk for adverse foetal and neonatal outcomes, compared to LO-PE and to no preeclamptic population. However, the newborn prognosis in terms of early neonatal death was not affected once adjusted for gestational age at birth. The difference in prognosis for perinatal death seems so probably conditional on higher rates of
MTP in EO-PE.

It worthwhile to note that among all preeclampsia in our population, 33\% were EO-PE, thus giving birth before 34 weeks of gestation and that among LO-PE, 29\% of women delivered between 34-36 weeks of gestation. As a consequence, even if neonatal outcome do not seem to be affected by preeclampsia per se, these results deserve concern, as preeclampsia accounts for a consistent number of preterm births in our population, which confers a significant health care burden. Indeed, infants born less than $<34$ weeks of gestation, like late preterm infants (34 through 36 weeks of gestation), are at higher risk of morbidity and mortality than term infants.

Another interesting finding of our work was that rates of preeclampsia were stable over the study period in our population, despite the alarming increase of obesity in pregnant women in Southern Reunion Island. Obesity is nowadays a recognized risk factor for preeclampsia (Jeyabalan 2013; Poorolajal and Jenabi, 2016). However, the mechanism underlying the link between preeclampsia and obesity is not completely understood, and the lack of parallelism between these two trends is another example of the heterogeneity of preeclampsia, especially in terms of risk factors.

For many years preeclampsia has been considered a complex, heterogeneous syndrome, described as a two-stage disease with different pathophysiology and clinical symptoms. With increasing knowledge, it appears that such a clear distinction in two stages is somewhat inadequate (Redman, 2014). From a pathophysiological point of view, for instance, it has recently been addressed that late-onset disease also is associated with findings of syncytiotrophoblast stress, which have been traditionally reported in the early-onset form (Redman and Staff, 2015). From a clinical perspective, our study shows that several symptoms more often associated to the late-onset clinical syndrome (insulin resistance, perturbed coagulation function, hypercholestoremia) are also found in EO-PE.

As our study is a retrospective analysis, it has some notable limitations. Some interesting data are lacking in the perinatal database,

Table 4

Foetal and neonatal outcomes in the study population and comparison between infants from EO-PE and LO-PE women.

\begin{tabular}{|c|c|c|c|c|c|c|c|}
\hline Variables & $\begin{array}{l}\text { No PE N = 59,665 N } \\
(\%)\end{array}$ & $\begin{array}{l}\text { LO-PE N = } 933 \mathrm{~N} \\
(\%)\end{array}$ & $\begin{array}{l}\text { EO-PE N = 464 N } \\
(\%)\end{array}$ & $\begin{array}{l}\text { LO-PE } v s \text { No PE p } \\
\text { value }\end{array}$ & $\begin{array}{l}\text { EO-PE } v s \text { No PE } \mathrm{p} \\
\text { value }\end{array}$ & $\begin{array}{l}\text { EO-PE } v s \text { LO-PE p } \\
\text { value }\end{array}$ & $\begin{array}{l}\text { EO-PE } v s \text { LO-PE p } \\
\text { adjusted for GA }\end{array}$ \\
\hline Gestational Age (weeks) & $38.4 \pm 2.4$ & $36.9 \pm 1.8$ & $30.4 \pm 2.27$ & $<0.0001$ & $<0.0001$ & $<0.0001$ & $\mathrm{na}^{* *}$ \\
\hline Birth Weight $(\mathrm{g})^{*}$ & $3085 \pm 585$ & $2617 \pm 601$ & $1228 \pm 436$ & $<0.0001$ & $<0.0001$ & $<0.0001$ & na** \\
\hline Female sex & $29,248(49.0)$ & $489(52.4)$ & $207(54.5)$ & $<0.0001$ & $<0.0001$ & ns & ns \\
\hline SGA & $4660(7.8)$ & $217(23.3)$ & $98(21.1)$ & $<0.0001$ & $<0.0001$ & ns & ns \\
\hline Apgar@1 min $\leq 3$ & $2709(4.5)$ & $93(10.1)$ & $111(27.1)$ & $<0.0001$ & $<0.0001$ & $<0.0001$ & ns \\
\hline $\begin{array}{l}\text { Need for intubation at } \\
\text { birth }\end{array}$ & $304(1.8)$ & $20(2.8)$ & $144(35.1)$ & $<0.0001$ & $<0.0001$ & $<0.0001$ & 0.007 \\
\hline Intrauterine foetal death & $524(0.9)$ & $12(1.3)$ & $31(6.7)$ & ns & $<0.0001$ & $<0.0001$ & ns \\
\hline $\begin{array}{l}\text { Medical termination of } \\
\text { pregnancy }\end{array}$ & $279(0.5)$ & $1(0.1)$ & $20(4.3)$ & ns & $<0.0001$ & $<0.0001$ & 0.02 \\
\hline Early neonatal death & $214(0.4)$ & $0(0.0)$ & $13(2.8)$ & ns & $<0.0001$ & $<0.0001$ & ns \\
\hline Perinatal death & $1017(1.8)$ & $13(1.4)$ & $64(13.8)$ & ns & $<0.0001$ & $<0.0001$ & 0.02 \\
\hline
\end{tabular}

* Values are expressed as mean $\pm \mathrm{SD}$

** Not appropriated. 


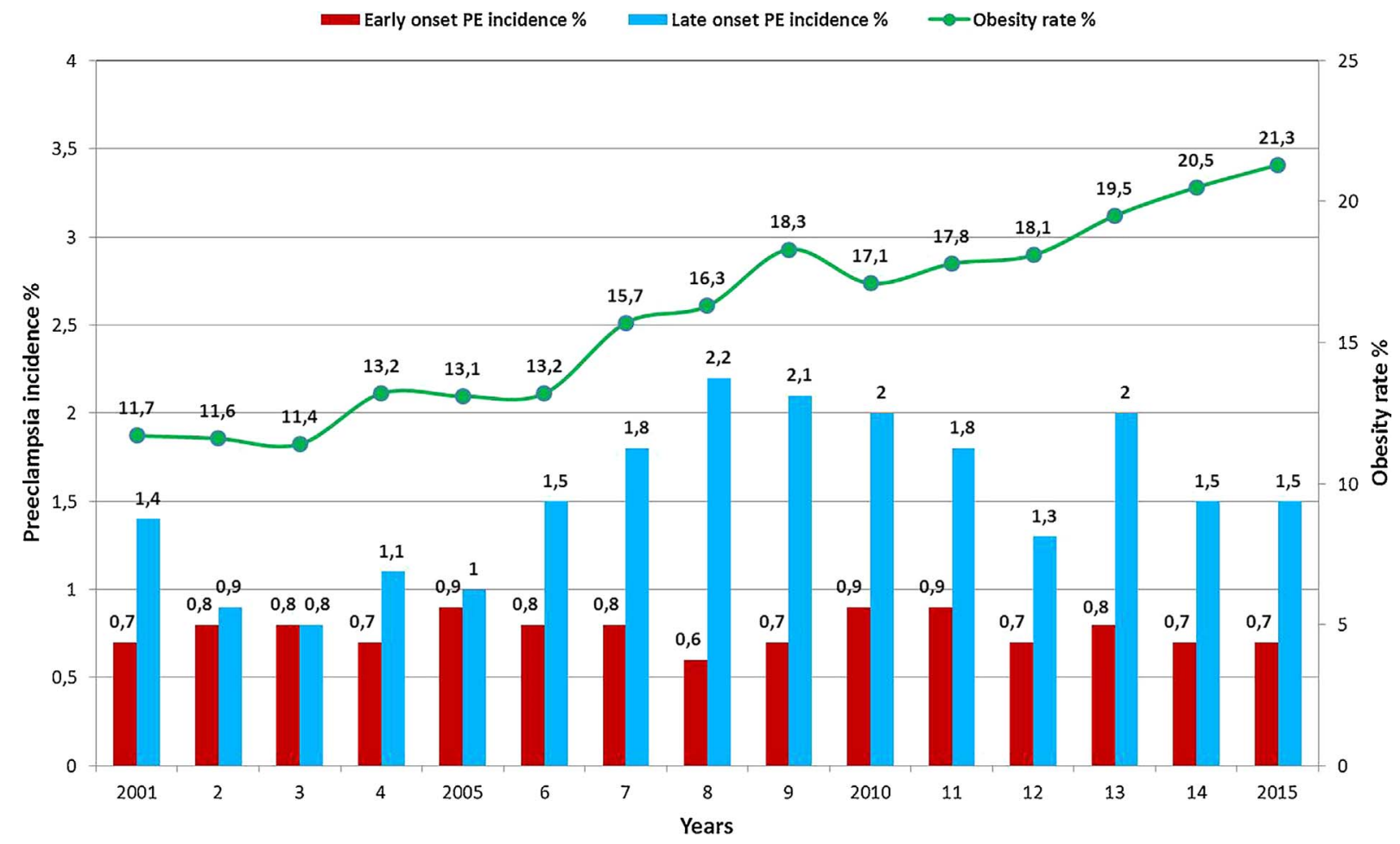

Fig. 1. Increasing trend of obesity in pregnant women at Reunion Island. Rates of EO and LO-PE are stable over the study period.

such as the notion of primipaternity, length of sexual relationship, recurrent pre-eclampsia, maternal inflammatory state, thrombophilia and we acknowledge that this information could add an useful contribution to the exploration of risk factors associated to EO or LO subtype.

The strength of our study includes a large cohort sample from a specific geographic area which is very representative of the regional population.

\section{Conclusion}

In conclusion, even if compared to LO-PE EO-PE is a pathophysiologically distinct and more severe clinical entity with earlier gestational age onset and delivery, this study failed to identify a specific phenotype of preeclampsia in terms of predisposition or pre-existing risk factors for one form or another. Of course the complexity of the disorder and the wide range of interactions among risk factors associated to preeclampsia warrant further investigations. Few additional significant differences in terms of associated maternal morbidities appeared between the two groups when the analysis dichotomized for preterm versus term delivery, but these were not striking. Future research should be targeted on the identification of a more appropriate gestational age cut off for defining EO and LO-PE, with a special focus on factors influencing neonatal outcome in infants born from preeclamptic mothers.

\section{References}

Aksornphusitaphong, A., Phupong, V., 2013. Risk factors of early and late onset preeclampsia. J. Obstet. Gynaecol. Res. 39 (3), 627-631.

Brenner, W.E., Edelman, D.A., Hendricks, C.H., 1976. A standard of fetal growth for the United States of America. Am. J. Obstet. Gynecol. 126, 555-564.

Chaiworapongsa, T., Chaemsaithong, P., Yeo, L., Romero, R., 2014. Pre-eclampsia part 1: current understanding of its pathophysiology. Nat. Rev. Nephrol. 10 (8), 466-480.

Elvedi Gasparovic, V., Beljan, P., Gveric Ahmetasevic, S., Schuster, S.S.S., 2015. What affects the outcome of severe preeclampsia? Signae Vitae 1 (Suppl (10)), 6-12.

Iacobelli, S., Bonsante, F., Robillard, P.Y., 2015. Pre-eclampsia and preterm birth in

Reunion Island: a 13 years cohort-based study. Comparison with international data.

J. Matern. Fetal Neonatal Med. 29 (18), 3035-3040.

Jeyabalan, A., 2013. Epidemiology of preeclampsia: impact of obesity. Nutr. Rev. 71
(Suppl 1), S18-25.

Kucukgoz Gulec, U., Ozgunen, F.T., Buyukkurt, S., Guzel, A.B., Urunsak, I.F., Demir, S.C., Evruke, I.C., 2013. Comparison of clinical and laboratory findings in early- and lateonset preeclampsia. J. Matern. Fetal Neonatal Med. 26 (12), 1228-1233.

Lisonkova, S., Joseph, K.S., 2013. Incidence of preeclampsia: risk factors and outcomes associated with early- versus late-onset disease. Am. J. Obstet. Gynecol. 209 (544), e1-12.

Lisonkova, S., Sabr, Y., Mayer, C., Young, C., Skoll, A., Joseph, K.S., 2014. Maternal morbidity associated with early-onset and late-onset preeclampsia. Obstet. Gynecol. 124 (4), 771-781.

Madazli, R., Yuksel, M.A., Imamoglu, M., Tuten, A., Oncul, M., Aydin, B., Demirayak, G., 2014. Comparison of clinical and perinatal outcomes in early- and late-onset preeclampsia. Arch. Gynecol. Obstet. 290 (1), 53-57.

Milne, F., Redman, C., Walker, J., Baker, P., Bradley, J., Cooper, C., de Swiet, M., Fletcher, G., Jokinen, M., Murphy, D., Nelson-Piercy, C., Osgood, V., Robson, S., Shennan, A. Tuffnell, A., Twaddle, S., Waugh, J., 2005. The pre-eclampsia community guideline (PRECOG): how to screen for and detect onset of preeclampsia in the community. BMJ 330, 576-580.

No authors listed, 2000. Report of the national high blood pressure education program working group on high blood pressure in pregnancy. Am. J. Obstet. Gynecol. 183, $1-22$.

Ny, Y., Cheng, W., 2016. Comparison of indications of pregnancy termination and prognosis of mothers and neonates in early- and late-onset preeclampsia. Hypertens. Pregnancy 35 (3), 315-322.

Poorolajal, J., Jenabi, E., 2016. The association between body mass index and preeclampsia: a meta-analysis. J. Matern. Fetal Neonatal Med. 9 (22), 3670-3676.

Redman, C.W.G., Staff, A.C., 2015. Preeclampsia, biomarkers, syncytiotrophoblast stress, and placental capacity. Am. J. Obstet. Gynecol. 213 (4 Suppl), S9-11 (S9. e1).

Redman, C.W.G., Sargent, I.L., Staff, A.C., 2014. IFPA senior award lecture: making sense of pre-eclampsia - two placental causes of preeclampsia? Placenta 35, S20-S25.

Redman, C.W.G., 2014. The six stages of pre-eclampsia. Pregnancy Hypertension. Int. J. Women's Cardiovas. Health 4, 241-247.

Robillard, P.Y., Dekker, G., Chaouat, G., Hulsey, T.C., 2007. Etiology of preeclampsia: maternal vascular predisposition and couple disease?mutual exclusion or complementarity? J. Reprod. Immunol. 76 (1-2), 1-7.

Robillard, P.Y., 2014. Rapport 2001-2014 Du Relevé épidémiologique périnatal Sud Réunion. https://www.repere.re/fileadmin/user_upload/RAPPORT_Epidemio_2014_ Sud-Reunion.pdf.

Sibai, B., Dekker, G., Kupferminc, M., 2005. Pre-eclampsia. Lancet 365 (9461), 785-799.

Steegers, E.A., von Dadelszen, P., Duvekot, J.J., Pijnenborg, R., 2010. Pre-eclampsia. Lancet 21 (376(9741)), 631-644.

Stubert, J., Ullmann, S., Dieterich, M., Diedrich, D., Reimer, T., 2014. Clinical differences between early- and late-onset severe preeclampsia and analysis of predictors for perinatal outcome. J. Perinat. Med. 42, 617-627.

Vatten, L.J., Skjaerven, R., 2004. Is pre-eclampsia more than one disease? BJOG 111, 298-302. 